\title{
The awareness levels on HIV/AIDS among garment women workers in Bangladesh
}

\author{
Sadika Sharmin ${ }^{1,2^{*}}$, MohdIsa $^{2}$, Wan Abdul Manan ${ }^{2}$ \\ ${ }^{1}$ Department of Rural Sociology, Bangladesh Agricultural University, Mymensingh-2202, Bangladesh \\ ${ }^{2}$ Programme in Nutrition, School of Health Science, Universiti Sains Malaysia, 16150 Kota Bharu, \\ Kelantan, Malaysia.
}

\begin{abstract}
The study aims to know the degree of awareness on HIV/AIDS among women workers working in garment industries of Bangladesh. The study was developed from data of secondary sources. The married, educated, older lady artisans and also who were contacted with media had good percentage of alertness on the epidemics of HIV than others. But they carried an unclear and hazy picture of AIDS inside them. Respecting means of transference, signs of HIV/AIDS, risk groups, mastery of prevention-their judgements were so diversified. Using contraceptives, joining in workshops connected with HIV - the rate was not competent. Of all the informants relevant to HIV/AIDS, hearing from radio/TV ranked the top. An effective, constructive and useful step should be taken by different government and non-government organizations to make the women wear employee having a clear and right conception to defence themselves from this transmissive and deathly disease.
\end{abstract}

Key Words: Awareness, HIV/AIDS, garment, women, Bangladesh

\section{Introduction}

Human Immunodeficiency Virus (HIV) is a virus which is a main causing factor of the killer disease Acquired Immune Deficiency Syndrome (AIDS) (Akter and Rahman, 2009; Mondal et al., 2012). As a global crisis, it was recognized by the mid-1980s (Kiragu, 2001). HIV is a parasite virus that makes destruction of the CD-4 cells (T-cells) and makes a body susceptible to a wide variety of opportunistic infections (Salam and Yousuf, 1995; Mondal et al., 2012). Sometimes the patient is incapable to defence against some illnesses and recover from other disorders (Mondalet al., 2012). The HIV is generally transmitted through unprotected sexual contact, heterosexual or homosexual, blood transfusion, donated semen or organs, contaminated needles (infection) or through infected women to their coming children (Hasan et al., 2013; Mondal et al., 2012). The presence of a genital ulcer caused by syphilis, chancroid or herpes increases one's vulnerability of HIV infection 10-20 times and the risk increases 3-4 times in case of gonorrhoea or chlamydia (Nasreen, 2001). In the month of June, 1981, the case of AIDS was first recognized in the USA (CDC, 2001). Approximately 34 million people were living with HIV in the world wide, also 2.7 million new HIV infections, including an estimated 390,000 cases among children, predicted at the end of 2010 (UNAIDS, 2011). Around 1.8 million people died of AIDS related causes in 2010 (UNAIDS, 2010). Once any AIDS patient is diagnosed in a developing country, the possibility of survival is not more than 2 years. In the South-East Asia, more than $80 \%$ of infections relating to AIDS caused by heterosexual transmission (SEARO, 2000). As for not having any vaccine, the prevention is only to control HIV infection and AIDS (Salam and Yusuf, 1995).

Bangladesh is not under the high risk of HIV (UNICEF, 2009; Mondal et al., 2012), but the general mass, especially the poor people and devastated women are still in the dark of the epidemiology of HIV. The study aims to have a general look on the discernment of AIDS among the garment women workers who are the main driving force of export business in Bangladesh.

\section{Methodology}

The study was based on desk research. Different papers and articles on the pervasiveness of HIV/AIDS in Bangladesh and other countries, alertness on it with the garment women workers, their knowledge levels were focused in this article to have a good concluding remark on these aspects.

\section{Prevalence of AIDS in Bangladesh}

\section{Discussion}

Bangladesh is fortunate as having low HIV/AIDS prevalence of less than 0.1\% (UNICEF, 2009; Mondal et al., 2012). However, it is threat for the health of the people. There are factors responsible for this like geographic location, high numbers of transport workers, a large commercial sex industry, low rate of condom use, needle sharing among injecting drug users,gender inequality and violence, stigma and discrimination and the most importantly, lack of proper knowledge concerning safe sex among the mass of Bangladesh (Khan, 
2002; Sayem, 2010; WB, 2009). In Bangladesh, the first case of HIV was first identified in1989 (NASP, 2010) and since then, the number of HIV patients have been firmly increasing till now (Mondal et al., 2012). Chronologically, only 1495 HIV cases and 476 AIDS cases were active at the end of 2008 (UNAIDS, 2009). Since December 2010, it increased to 2088 incidents of HIV and 850 of AIDS patients were identified and among these, 241 died (NASP, 2010). Figure 1 shows the extent of HIV/AIDS in Bangladesh for several years.

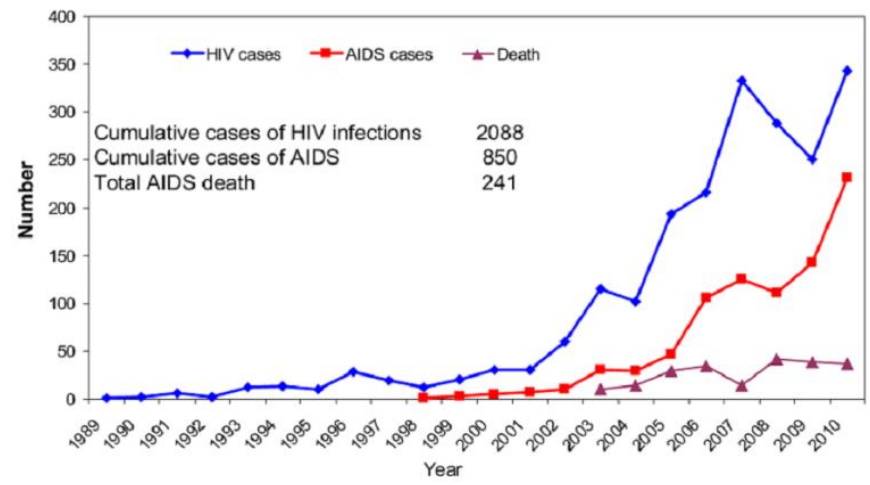

(Source: UNGASS Country Progress Report, NASP, MOHFW, Government of Bangladesh, 2011)

Figure 1. Reported HIV and AIDS Cases and Deaths in Bangladesh from 1989 to 2010

\section{Difference of HIV/AIDS Knowledge at Several Categories}

To prevent HIV/AIDS epidemic, public aliveness is specified to have a dominating part (Mitra and Associates, 2004). Different socio-economic indicators like age, education, marital status, birth place, listening and access to media, having jobs in outside etc. play a vital role in enriching the knowledge on HIV/AIDS. Studies showed that there was an association between age and level of intelligence of garment women workers. Those who were in the age group of 17-19 years had better understanding on HIV than below the age of fourteen (Hasan et al., 2013). Comparing to illiterate apparel workers and literate wear labourers were 3.37 times more educated to have knowledge on HIV. Similarly, married skilled workers showed the same result by focusing that unmarried hands were 1.97 points lower attentive of AIDS than them (Mondal et al., 2008).

Education of spouses also makes a family more convenient to use preventive methods. The women workers husbands who had secondary or higher secondary level of education, used contraceptives one and half time more than other workers whose hubbies had no formal education. The uses of different preventive methods (condom, pill, diaphragm, foam, jelly, loop, ring, rubber, sponge, intrauterine device, coil, rhythm method etc.) were higher among the women bread-winners who had conversations of family planning with their husbands than those who did not (Ali, 1998).

Place of birth (rural or urban) also plays a significant factor to generate a good idea referring to HIV. Studies revealed that the workers identified as urban by place of origin,hadgood perception of HIV by 2.11 times more than rural one (Mondal et al., 2008).

Listening is one of the most reported sources and strong predictor of accomplishing is much updated picture on HIV. This connection made them well-rounded 3.32 times higher than non-listener partners in wear industries. Listening to radio programmes dealing with AIDS made habiliment drudges 6.41 points more alive than their counterparts.

Now-a-days, media has a very nice act to make a person human being.Having entry to media information made raiment artisans 2.34 times more likely renovated in HIV knowledge than those who had not access to media information. Through radio and TV programmes, large proportions (57\% and 70\% respectively) of the workers were concerned on the subject of HIV. The television watching garb labourers were 7.12 times more enlightened comparing other workers (Mondal et al., 2008).

The women who work outside have better apprehension of AIDS than housewives. The working ladies had 1.8, 4.7 and 10.8 times more probability in listening, having acquaintance of HIV and consistency of condom in preventing this virus (Akter and Rahman, 2009).

Apart from spouse-leaving behind husbands/wives in own home towns or villages fuels the extra marital sexual attraction in costume workers and is also identified as one of the major social cause of spreading AIDS among them (Mondal et al., 2008).

\section{Knowledge/Awareness on HIV among garment women workers in Bangladesh}

HIV/AIDS is now a common dialect to everyone. Almost all of the workers (98.3\%) heard this word in get-up factories of Bangladesh. Around ninety one per cent of them knew that this attack is transmissible from one person to another (Hasan et al., 2013). Additionally, it breaks the immune system and makes a man too 
vulnerable to any kind of unsoundness-cultured by more than seventy per cent of blue-collar employees (Mondal et al., 2008).But the apprehensive on this facet is not sufficient amidst them. The study examined that most of them had poor (76.9\%) consciousness while thirteen per cent had average and only eleven per cent had good observation on this manner (Hasan et al., 2013).

It happens mainly by sexual intercourse- learned by nearly eighty per cent of labourers. Multiple sex partners are a mode of transmission- thought by more than one third of them. There are other causes conceived by them as through blood transfusion (38.5\%), intravenous drug abuse (13\%), by equipment and needles (40\%), mother to child transmission (20\%), homosexuality (4.8\%) are the risky routes of being affected in HIV. Only four per cent estimated that it was not transmissible and five per cent did not know anything on this matter.

Among the artisans, there are misconceptions with regard to the symptoms of HIV. They thought fever (64.3\%), fatigue (45.2\%), weight loss (29.8\%), malaise (22.6\%), rash (19\%), chronic diarrhoea (10.7\%), sore throat $(11.9 \%)$, night sweating $(8.3 \%)$ and other causes $(22.6 \%)$ as the features.

The habiliment labourers had different opinions of high-risk groups in HIV. They assumed that persons having heterosexual partners including prostitutes (64.4\%), multiple sex partners (39.9\%), doing blood transfusion $(21.8 \%)$, bus drivers or rickshaw pullers $(11.4 \%)$ were at high risk groups. But closely twenty per cent had no idea regards that (Hasan et al., 2013).

The rate of having general knowledge on prohibition of HIV/AIDS is high among the working women. Closely seventy four per cent of workers perceived that HIV is preventable and forty five per cent expected it is curable (Hasan et al., 2013). But another statistics showed that HIV is treatable - had knowledge by more than ninety per cent of factory workers and they also knew the treatment of this illness (Mondal et al., 2008). Mostly avoiding heterosexuality including prostitutes $(71.9 \%)$, multiple sex $(47.1 \%)$, homosexuality and bisexuality (5.9\%), using condoms (43.4\%), skipping sharing of needles and syringes (38.0\%), screening of donated blood (20.4\%), preventing vertical transmission (6.8\%), discouraging sharing of tooth brushes and razors $(3.6 \%)$ - they thought they could protect themselves from AIDS. Alternatively, the ratio of thinking that HIV is not preventable -judged by only nine per cent and approximately seventy one per cent labourers concluded that death is the ultimate fate of this condition (Hasan et al., 2013).

Using contraceptives prevents a person from HIV and also from so many contagious epidemics. But among the vestments women workers, half of them $(43 \%)$ did not use any contraceptives. Studies showed that the outfit manual workers using contraceptives were 9.44 times more conscious of HIV. AIDS is a terrible and life threatening disease and it also losses preventing power and increases physical weakness. Though almost all of the workers (94\%) were alert regarding that, but sixty four per cent of them had not participated in any seminar/workshop related with that. The joining ladies were 8.38 times more attentive of AIDS. On the contrary, ninety one per centattended in the company programmes of HIV.But their knowledge regarding prevention was not satisfactory.

Awareness is also created in them both by outside people and themselves. With the help of other persons, high percentages (90\%) of working stiff were conscious in connection with this misery. It was 8.88 times more of being familiarof this sickness informed by others (Mondal et al., 2008).

There were so many diversified sources of acquiring knowledge on HIV/AIDS. Studies showed that a large number of operators were well known of AIDS from clinics (27.5\%) and health workers $(25.83 \%)$. Education on AIDS was also gathered from friends and relatives (17.5\%), husband (12.5\%), Non-government organizations (7.5\%), television and radio (5\%) and from others (4.17\%) (Begum and Hussain, 2008). Another study presented that the ratio of hearing from Radio/TV about HIV is the highest-approximately eighty three per cent. From rest of the informants like newspapers (8.1\%), friends (11.7\%), health workers (6.4\%), books (4.7\%) and organized AIDS education program (3.7\%) they gathered insights of it (Hasan et al., 2013).

Regarding knowledge on non-contraceptive use of condoms like protection from HIV, syphilis, gonorrhoea etc. literature manifested that around eighty seven per cent workers had no idea about it and only thirteen per cent were concerned of other uses of condoms. Half of them $(50 \%)$ learned it from television and the rest of them from doctors and husband (18.75\%) and from health workers (12.5\%) (Ali, 1998). Familiarity regarding AIDS encompassed by slum women meant by ever heard of this sickliness, be wise of avoiding AIDS by condom use were also significantly lower mid women in blighted area (Khan and Kraemer, 2008).

Studies revealed that roundly ninety one per cent coveringwomen workers used contraceptives with the mutual understanding of both husband and wife, seven per cent due to self-desire and only three per cent exercised it being motivated by their spouses (husbands) (Begum and Hussain, 2008). There was also another dialogue that due to husband's desire, the proportion of using preventive methods was ten per cent among togs women workers (Ali, 1998).

It was dictated that practically eighty four per cent workers had an adequate knowledge, sixteen per cent had some observation and one per cent had no idea on contraceptive methods. There are also so many gynaecological, educational and familial reasons for not using contraceptives among the uniform women workers. For not having interests of husband (28.56\%), due to side effects and irregular menstruation (21.43\%) 
and wants conception and not living with husband (14.29\%) were dominant of all the causes-proved by the previous researches (Begum and Hussain, 2008). However, a study carried out by Roberts showed otherwise that, the workers were instructed of health education under health insurance scheme and almost all of the labourers were awake of this aspect (Roberts, 2001).

Of all the controlling methods, condom was found as the least adopted method for having low level of education, allergy to rubber and chemicals and misconception towards condom (Begum and Hussain, 2008).

\section{Conclusion}

There is some dissimilarity of the recognition devoted HIV/AIDS- surrounded by garment women workers. Several socio-economic factors made a wide difference of being accustomed with this dangerous killer disease. They had knowledge of both the severity and protective measures of this misery.Having low literacy rate, the array women workers are not informed of menstruation, safe sex, contraceptive methods and HIV infection.

\section{Acknowledgements}

The authors acknowledge to the Universiti Sains Malaysia Fellowship (USM Fellowship) to support this study.

\section{References}

[1]. Akter S and M Rahman. 2009. Socio-demographic Covariates Play a Tremendous Role in Mounting HIV/AIDS Awareness, Knowledge among Slum Women in Bangladesh. Revista de CienciasMedicas e Biologicas, 8:250-255.

[2]. Ali S. 1998. South Asian Perspective on Fertility Regulation. $8^{\text {th }}$ Postgraduate Course for Training in Reproductive Medicine and Reproductive Biology.Geneva Foundation for MedicalEducation and Research.

[3]. Begum M and A Hussain. 2008. Study on the Acceptance of Contraceptive Devices Among Married Female Workers of A Garments Factory of Dhaka City. Bangladesh J PhysiolPharmacol. 24:10-13.

[4]. CDC. 2001."Morbidity and Mortality Weekly Report," centre for Disease Control and Prevention, Vol 50, No.21.

[5]. Hasan T, M Hassan, R Khan, R Nuzhat and E Arefin. 2013. Influence of Socio-demographic Factors on Awareness of HIV/AIDS among Bangladeshi Garment Workers. Springer Plus. 2013:1-7,doi: 10.1186/2193-1801-2-174.

[6]. Khan M and A Kraemer. 2008. Socio-economic factors explain differences in public health-related variables among women in Bangladesh: A cross-sectional study. BMC Public Health. 8:1-10.

[7]. Khan M. 2002. Knowledge on AIDS among Female Adolescent in Bangladesh: Evidence from the Bangladesh Demographic \& Health Service Data. J Health Pop Nutrition, 20: 130-137.

[8]. Kiragu K. 2001. Youth and HIV, AIDS: Can We Avoid Catastrophe? Johns Hopkins University Bloomberg School of Public Health, Center for Communications Programs, Population Information Program.

[9]. Mitra and Associates.2004. Bangladesh Demographic and Health Survey 2004, Dhaka, Calverton:NIPORT,Mitra and Associates, Macro International.

[10]. Mondal I, RIslam, ORahman, SRahman and N Hoque.2012. Determinants of HIV/AIDS Awareness among Garments Workers in Dhaka City, Bangladesh. World J AIDS, 2:312-318.

[11]. Mondal N, M Hossain and M Rahman. 2008. Knowledge and Awareness about HIV/AIDS Among Garments Workers in Gazipur District, Bangladesh. Social Sci. 7:528-530.

[12]. NASP. 2010. "UNGASS Country Progress Report," National AIDS/STD Programme, Ministry of Health and Family Welfare (MOHFW), Government of Bangladesh.

[13]. NASP. 2011. "UNGASS Country Progress Report," National AIDS/STD Programme, Ministry of Health and Family Welfare (MOHFW), Government of Bangladesh.

[14]. Nasreen H. 2001. Reproductive Tract Infections and Sexually Transmitted Diseases in a Rural Area of Bangladesh: Insights for Action from Research. Master's Thesis in Public Health Epidemiology, Department of Public Health \& Clinical Medicine, Umea University, Umea, Sweden.

[15]. Roberts B. 2001. Reproductive health services for garment factory workers in Bangladesh. Harare, SAf AIDS, Sexual Health Exchange 2001/04.

[16]. Salam A and R Yousuf.1995. AIDS Awareness in Bangladesh- A Cross sectional study. Sir Salimullah Med College J. 3:38-42.

[17]. Sayem A. 2010. An Assessment of Risk Behaviours for HIV/AIDS among Young Female Garment Workers in Bangladesh. Inter J STD \& AIDS, 21:133-137.

[18]. SEARO.2000. A Health Profile-Women of South-East Asia. WHO Regional Publications, New Delhi, India.

[19]. UNAIDS. 2009. "20 Years of HIV in Bangladesh: Experience and Way Forward", UNAIDS.

[20]. UNAIDS. 2010. "UNAIDS Report on the Global AIDS Epidemic", UNAIDS

[21]. UNAIDS. 2011. "World AIDS Day Report", UNAIDS.

[22]. UNICEF. 2009. BangladeshStatistics, http://www.unicef.org/infobycountry/bangladesh_bangladeh_statistics.html.

[23]. World Bank. 2009. "HIV/AIDS in Bangladesh", The World Bank, www.worldbank.org/bd, www.worldbank.org/statistics. 